\title{
Apontamentos sobre o figurino entre as artes cểnicas e visuais
}

Notes on the costume design between the performing and visual arts

Manoel Silvestre Friques ${ }^{1}$ 


\section{Resumo}

Neste artigo, são apresentadas obras e processos artísticos que possuem, como ponto de partida, a manipulação de procedimentos comuns ao ofício do figurinista. Sendo assim, procura-se observar aqui as diversas maneiras encontradas por alguns artistas-figurinistas para transformar a costura, o bordado, a tecelagem, dentre outros fazeres, em proposições estéticas. Antes de reforçar a separação entre as artes cênicas e as visuais, propõe-se então a consideração destas como um campo híbrido e ampliado no qual situam-se as obras de Bob Wilson, Cindy Sherman, Leonilson, Bispo do Rosário, Letícia Parente e Sheila Hicks.

Palavras-Chave: Figurino; costura; campo ampliado

\section{Abstract}

This article presents works and artistic processes that have, as a starting point, the manipulation of the common procedures of the costume designer. So, the intent here is to observe the various ways found by some artists-costume-designers to transform sewing, embroidery, weaving, among other practices, in aesthetic propositions. Instead of reinforcing the separation between the visual and performing arts, so it is proposed to consider these as a hybrid and expanded field in which lie the works of Bob Wilson, Cindy Sherman, Leonilson, Bispo do Rosário, Letícia Parente and Sheila Hicks.

Keywords: Costume Design; sewing; expanded field

ISSN: 1414.5731

\footnotetext{
${ }^{1}$ Doutorando junto ao Programa de História Social da Cultura (PUC-Rio). Professor Auxiliar da Escola de Engenharia de Produção com ênfase em Produção Cultural (UNI$\mathrm{RIO})$. Rio de Janeiro (RJ). manoel.friques@gmail.com
} 


\section{Sobre a necessidade, sempre problemática, das linhas divisórias}

Em estudo seminal - em âmbito brasileiro - sobre a obra de Robert Wilson, Luiz Roberto Galizia dedica algumas páginas à análise de exposições do encenador norte-americano produzidas na década de setenta, em especial aquelas ocorridas no Musée Galliera (Paris, 1974) e na Galeria Goodman (Nova York, 1978). Essas mostras exibiam "desenhos, esculturas e objetos, todos derivados de seus trabalhos teatrais", isto é, "criações pós-teatrais, nas quais os acessórios são isolados das peças, como objetos artísticos independentes" (Galizia, 2004, p. 90 e 95). Se, para o autor, os desenhos e projetos expostos não apresentam a menor teatralidade, no caso da série de cadeiras - originalmente integrante dos espetáculos A vida e a época de Joseph Stalin (1973) e Uma carta para Rainha Vitória (1974) - verificar-se-ia qualidade inversa, ou seja, um "apelo teatral óbvio". Tal diagnóstico o faz questionar a linha divisória que separa o espaço teatral de um ambiente expositivo voltado especificamente às artes visuais:

\footnotetext{
A tensão dramática criada entre duas cadeiras vazias, que se confrontam, é a mesma tensão dramática criada por duas pessoas sentadas naquelas mesmas cadeiras? [...] A construção de um cenário teatral em torno de um objeto comum acaso lhe transmite uma impressão dramática? (Galizia, 2004, p. 93).
}

Por mais que tais objetos remetessem ao seu contexto original, cumprindo então uma função arqueológica, não seria tal referência que atestaria a sua dimensão teatral. Para Galizia, o modo como tais elementos pós-teatrais, isolados de seu contexto dramático original, estavam dispostos no espaço expositivo, indicava a permanência de uma dimensão teatral. Tal presença do teatro para além das fronteiras do acontecimento cênico faz com que o autor problematize a fronteira entre essa manifestação artística e as artes visuais.

O cuidadoso olhar do analista para esses trabalhos de Wilson, que o leva a refletir a respeito das permeabilidades entre as artes, nos ajuda, com certa precisão, a introduzir aqui o tema desta reflexão. Pois, tal como as páginas que ele dedicou aos elementos pós-teatrais, propomo-nos a refletir a respeito do figurino despido de seu contexto teatral (fato que não atesta, como vimos no caso do encenador norte-americano, a inexistência de uma dimensão teatral). A empreitada tem origem no seguinte conjunto de indagações que nos serve de desafio: é possível pensar o figurino para além de sua inserção, como elemento cênico, no complexo sistema teatral? 0 figurino pode ser uma obra de arte autônoma, ou deve ele depender sempre do dispositivo teatral constituído por outras atividades (ou sistemas semiológicos), como encenação, dramaturgia, iluminação, cenário, direção de arte, direção musical etc.? O figurino sobreviveria ao acontecimento teatral?

Para tornar a reflexão em curso ainda mais instável, retomemos um trabalho recente de Bob Wilson, os seus vídeos em high definition apresentados em São Paulo (Sesc, 2008) e no Rio de Janeiro (Instituto Moreira Salles, 2010). Trata-se de um conjunto de retratos videográficos, sob o título Voom Portraits e com duração média de poucos minutos cada, onde estamos diante de grandes celebridades emprestando as suas personas a outros personagens. A natureza da empreitada estabelece, de ime- 
diato, um elo entre Wilson e Andy Warhol, em especial os Screen Tests desenvolvidos pelo segundo entre 1964 e 1966. Por meio dessa série de retratos em vídeo - onde os indivíduos focalizados foram orientados a permanecer imóveis por algum tempo -, o idealizador da Factory elaborou uma espécie de arqueologia do tempo presente, registrando, em cerca de 500 rolos, os personagens que habitavam o seu artworld. Caracteriza essas obras uma espécie de crueza: os sujeitos diante da câmera compartilham com o observador o tédio do observado, em uma recuperação da imagem fotográfica do período anterior a sua industrialização.

Pode-se dizer que o "nada-a-fazer" dos retratados de Warhol apresenta uma espécie de retomada dos procedimentos pioneiros da fotografia, cujas imagens eram produzidas a partir da imobilidade dos objetos fotografados. Se os primeiros aparelhos fotográficos necessitavam que seus modelos permanecessem imóveis, pois a longa exposição assim os solicitava, nos Screen Tests de Warhol, o mesmo recurso produz uma aura que se dá a ver justamente pelo que estamos aqui nos referindo como uma espécie de entendiante letargia. A aura decorrente daí não é a mesma dos primórdios da fotografia, que Benjamin descreveu apropriadamente em 1931. Sem dúvida alguma, ambas levam "o modelo a viver não ao sabor do instante, mas dentro dele" (Benjamin, 1999, p. 96). No entanto, enquanto nas imagens de fotógrafos como David O. Hill (1802-1870), a duração dá forma à pose, nos Screen Tests de Warhol, a duração a desfaz.

A crueza do mundo retratado nos vídeos de Warhol cede lugar, em Wilson, a um universo decididamente ficcional. Além disso, o encenador não elege aspirantes à celebridade - como fizera Warhol, pontuando assim uma ambiguidade entre a marginalidade dos aspirantes e a magia das estrelas -, mas figuras públicas reconhecidas em âmbito internacional, "deuses de nosso tempo" ${ }^{2}$. Nos screen tests de Wilson, as celebridades surgem como protagonistas de universos explicitamente teatrais, produzindo, sob a ótica de Rodrigo Naves, diferenciações no discurso hegemônico das imagens na contemporaneidade. Pois, para o crítico, há nesse trabalho de Wilson uma operação de superfície devedora de Beckett que elimina, por sua vez, a interioridade do drama burguês. O encenador norte-americano lida com os instrumentos da vertente hegemônica da imagem (repetição, dissociação entre som e imagem etc.) para, a partir deles, possibilitar o vislumbre de um mundo de modo interessante e inédito. De acordo com Naves, tal percepção é capaz não de restituir uma realidade primeira, mas de devolver minimamente a nossa capacidade de discriminação das coisas do mundo. E tudo isso pela superfície.

A menção a Beckett, não é, de fato, gratuita. O voom portrait de Winona Ryder comprova o vínculo, sendo uma espécie de pílula beckettiana sintetizada por Wilson a partir de uma das obras-primas do dramaturgo britânico. Nesse retrato, a atriz encontra-se soterrada de terra até os ombros, tal como a personagem Winnie em Dias Felizes. Como as outras celebridades, Ryder permanece imóvel, tendo pequenos

\footnotetext{
2 Esta é a citação na íntegra, retirada do catálogo da exposição Voom Portraits: "Um homem da rua, um animal, uma criança, super stars, deuses de nosso tempo". Cabe ainda destacar que esta série de Wilson tem origem em trabalho anterior realizado na década de 70 e intitulado Video 50: "Fiz retratos,
}

incluindo o escritor surrealista Louis Aragon, a socialite Helena Rochas, um pato, um padre que eu conheci num bar, o diretor de museu Pontus Hulten, ○ CEO da Sony, Akito Morita, e o Ministro da Cultura da França Michel Guy" (SESC, 2008). 
movimentos com a cabeça (a atriz acompanha a passagem da luz solar), articulando, ao quadro estático, um enfoque duplo do movimento (a pose somada ao gesto destacado).

Já na montagem teatral da peça realizada por Wilson, na qual Winnie é interpretada pela atriz Adriana Asti, a junção do minimalismo gestual investigado pelo diretor à (aparente) imobilidade da personagem principal enfatiza a estaticidade do quadro, "pinturas e esculturas vivas" nas quais sobressaem os movimentos de luz, as expressões faciais de Asti e também o peso existencial do texto. Soterrada até a cintura, no primeiro ato, e com apenas o pescoço descoberto no segundo, Winnie permanece imóvel durante toda a peça, sem haver, com isso, uma ausência de ação. Dois planos se sobrepõem nessa obra: aquele onde vemos a personagem sob a terra e outro criado a partir de seu longo monólogo. Em outras palavras, a banalidade da rotina mascara o soterramento da morte.

As duas Winnies de Wilson parecem ilustrar a dinâmica incessante presente em todas as obras do diretor: de um lado, uma cena levada aos limites da imobilidade, de outro, um retrato que se move. Retrato e cena, movimento e inércia imbricamse nestes trabalhos, não havendo aqui polaridades. Pelo contrário, as Winnies, de Ryder e de Asti, complementam-se de modo peculiar revelando lados e ritmos de uma mesma poética.

Mas os Voom Portraits são cenas que exigem, como uma produção teatral elaborada, uma equipe de profissionais incluindo aí cinegrafista, técnico de som, figurinista, cabeleireiro e maquiador. Tal como acontece em suas produções teatrais, Wilson ficou nessa série responsável pelo cenário e pela iluminação. Esse fato não nos permite enxergar, tal como queria Michael Fried, uma separação entre os universos das artes visuais e das artes cênicas. Falar, portanto, em figurino nas artes visuais não pressupõe a sua emancipação da cena. Pois, a exemplo da poética wilsoniana, há artistas cujas produções podem apresentar no espaço expositivo objetos e vestimentas despidos do contexto teatral e ainda imbuídos de caráter dramático; ou ainda apostar em pílulas cênicas situadas em espaços expositivos, na medida em que, por meio das novas tecnologias, retomam o gênero pictórico do retrato mantendo, com isso, uma equipe de produção próxima àquela característica do fazer teatral.

Por mais que Bob Wilson não seja figurinista, o caráter híbrido de sua trajetória artística e de suas produções institui um horizonte no qual se torna impossível delinear fronteiras nítidas. Uma vez que é nesse âmbito permeável que nos situamos, a figura do encenador norte-americano serve de mote para algumas precárias definições. Como já foi dito anteriormente, não custando nada vez ou outra reforçar, não se propõe aqui separar as artes cênicas das artes visuais. Sob outra perspectiva, pretende-se ampliar o campo de atuação do figurinista, percebendo, em um contexto expandido de produção artística, como determinados procedimentos, recursos, materiais e saberes podem ser mobilizados não apenas em acontecimentos teatrais tradicionais, mas também em contextos mais abrangentes, envolvendo aí todo o aparato cultural que constitui a arte contemporânea.

Nesse último contexto, supomos de grande valia mencionar a classificação elaborada por Cacilda Teixeira da Costa em seu livro Roupa de Artista - o vestuário na obra de arte. Nele, a autora observa "o desenrolar de um processo em que o vestuário evolui de elemento suplementar a protagonista" (Costa, 2009, p. 8). Para isso, Costa 
revê a história da arte a partir do Renascimento, instituindo uma linha divisória entre a representação e a autonomia do vestuário. Assim, como suplemento expressivo, o figurino é analisado em pinturas produzidas entre os séculos XIV e XIX, sendo ele um dentre os elementos que compõem a cena pictórica. De outro lado, como elemento plástico autônomo, o vestuário é entendido pela autora como uma

\footnotetext{
produção que se insere no campo dos novos meios, ao lado do vídeo, arte postal, cinema de artista, web art e outros [que] já esteve presente em quase todos os movimentos artísticos do século XX, na forma de vestimentas singulares, performances, empacotamentos, estamparias exclusivas, vídeo e outras tecnologias e continua contemporaneamente em transposições, apropriações e vestuários incomuns, entre outras manifestações (Costa, 2009, p. 9).
}

wLevando em consideração as designações de Costa, podemos dizer que as cadeiras de Wilson efetuaram a passagem da primeira à segunda categoria, enquanto que os vídeos do encenador recolocaram o suplemento expressivo no interior do elemento plástico. A poética híbrida de um artista múltiplo parece impor, com isso, sempre o fracasso das linhas divisórias; mesmo assim, o binômio de Costa revela-se adequado se não o encararmos como antitético, mas como substrato binário básico existente em qualquer produção artística, havendo apenas uma diferença de ênfase em uma ou outra categoria. Nesse sentido, no caso das cadeiras, a ênfase recai com maior força no elemento plástico, enquanto que nos Voom Portraits, ocorre movimento inverso. Isto não quer dizer, cabe ressaltar, que o primeiro caso não possa ser abordado como exemplo no qual as cadeiras sejam encaradas como suplemento expressivo e o segundo como uma situação na qual os recursos cênicos sejam elementos plásticos autônomos.

Esclarecido esse ponto, voltemos, neste momento, ao nosso desafio primeiro: como o figurino sobrevive ao acontecimento teatral? Ora, quando desejamos perceber o figurino para além das fronteiras teatrais, não queremos assim dizer. Na realidade, propomos focalizar a atividade do figurinista de modo não necessariamente dependente de um sistema teatral. Claro que a obra, inserida em uma galeria de arte, poderá apresentar uma dimensão dramática. Não é o figurino independente do teatro, mas sim o figurinista, como um artista visual liberto de um sistema hierárquico de produção (nesse sentido, importa pouco se o paradigma é textocêntrico ou cenocêntrico, pois a prática do figurinista estaria submetida a uma determinada visão, seja do dramaturgo, seja do encenador), que desejamos, a partir de agora, tematizar. Sob essa ótica, vamos analisar algumas trajetórias artísticas nas quais os recursos comuns ao figurino - material têxtil, a costura, a tecelagem, a caracterização - são o eixo da criação. Com isso, interessa-nos o vestuário enquanto elemento plástico autônomo, havendo ainda assim uma irredutível fração de seu caráter enquanto suplemento expressivo que não deverá ser desconsiderada.

\section{Arthur Bispo do Rosário e o desloucamento dos signos}

Ao se deparar com o trabalho de Arthur Bispo do Rosário, o analista invariavelmente lida com o fato de o criador não se autoproclamar um artista, mas um enviado de Deus. Isso porque Bispo, além de ser um outsider do circuito e do sistema de arte, 
habitava o que Susan Sontag (2007) chama de "zona noturna da vida", portando, por isso, uma cidadania onerosa.

Bispo emigrou do reino dos sãos para o dos doentes ao ser diagnosticado como esquizofrênico paranóico em 1938. Até então, o passaporte bom do negro sergipano nascido em 1911 the fora garantido por meio de suas competências ordinárias em atividades profissionais que incluíram lavador de carros, borracheiro da Light, segurança, porteiro, timoneiro e sinaleiro da Marinha, e também boxeador. $O$ fato decisivo na migração de Bispo é assim descrito por Wellisch:

Ocorreu no dia 22 de dezembro de 1938, à meia noite. Sete anjos em nuvens especiais, no formato de esteiras, foram buscá-lo na rua São Clemente, 301, Botafogo. Empunhando lança, em uma nuvem de espíritos malignos, foi ele assinalado com uma cruz de luz azul nas costas, para apresentar-se na Candelária, onde seria reconhecido como Jesus Cristo. Este evento está registrado em um dos estandartes de sua obra, como marca do eixo lógico condutor da história inscrita em sua "Nova" Escritura, feita de linha fundeada, ancorada em lençol. E as palavras entrançadas um dia se farão verdade (Wellisch, 2006, p. 40).

A partir desse momento, a residência de Bispo passou a ser um hospício: a Colônia Juliano Moreira, local onde ele viveria por mais de meio século, sendo descoberto no início da década de 80 por jornalistas e críticos ${ }^{3}$.

A fascinação decorrente da obra de Bispo do Rosário parece advir de uma combinação singular entre artesania e sistematização. Isto é, o criador, se não é um artista, utiliza o seu fazer artesanal na criação de um sistema classificatório inusitado, reunindo e organizando restos e trapos descartados diariamente pela sociedade. Ao recriar a divisão social a fim de apresentá-la no juízo final, o louco messias materializava um princípio de ordenamento - fundado em uma justificativa religiosa - que lhe servia de missão. Marginalizado do mundo, Bispo o recria deslocando-se da periferia ao centro. Ou, como diz Frederico Morais, crítico que realizou a migração do esquizofrênico ao reino dos artistas, "o delírio do Bispo era o conceito" (Morais apud Wellisch, 2006, p. 48).

Se Morais ${ }^{4}$ é o primeiro crítico brasileiro a conferir mérito artístico à arca de Bispo, seus companheiros de profissão apresentam maior cautela nessa passagem.

Para Wilson Coutinho, o realismo nominalista de Bispo "o limita como artista", posto que o criador é um "catalogador, um pouco mecânico, rendido à ordem" (Coutinho, 2008, p. 165). Luis Camillo Osório, por sua vez, preocupa-se em não reduzir a persona de Bispo sob o rótulo do artista historicamente determinado:

falar que aquilo não era arte era uma maneira de qualificar aquilo, no sentido de que tomar aquilo como arte, ou, apenas como arte, me parecia reduzir as possi-

\footnotetext{
${ }^{3}$ Wellisch assim descreve a "descoberta" de Bispo: "O jornalista Samuel Wainer Filho [...] capturou pela primeira vez a imagem de Bispo e sua obra, exibida, em cadeia nacional, no dia 18 de maio de 1980, pelo Fantástico [...], da [...] Rede Globo de Televisão. [...] Neste mesmo ano [...], o psicanalista e fotógrafo Hugo Denizart, [...] atravessou a rotina da Colônia Juliano Moreira, para documentá-la por meio de fotos e filmes. [...] Conseguiu entrevistá-lo, criando o filme $O$ prisioneiro da passagem - Arthur Bispo do Rosário, em $16 \mathrm{~mm}$, editado em 1982. [...] Frederico Morais, então, coordenador de artes plásticas do MAM, comovido pelo trabalho de Arthur Bispo, quis conhecê-lo em sua cela, na Colô-
}

nia Juliano Moreira" (Wellisch, 2006, p. 41).

4 Foi Fernando de Morais o responsável pela organização e curadoria da primeira exposição individual de Bispo, intitulada Registros de minha passagem pela terra: Arthur Bispo do Rosario e realizada postumamente na Escola de Artes Visuais Parque Lage, em 1989. 
bilidades de relação que aquela aura, aquelas obras, aquela pintura, tinha com o público. [...] Eu queria, justamente, com essa observação de que aquilo não era obra de arte, pensar em que medida essa especificidade psíquica do Fernando Diniz $^{5}$, catalogada como loucura, ela tem uma potência expressiva, e como essa potência expressiva da loucura, tangencia a questão artística, mas ela não se reduz à questão artística, na medida em que a questão artística implica num quadro de referência histórico - isso não quer dizer que seja o que interessa nas obras de arte, o quadro de referência histórico, mas há uma consciência histórica, há um pertencimento a uma história, há uma condição de possibilidade, de sentido artístico, que o artista de certa maneira assume, enfrenta, transforma, que aquela produção passa ao largo, o que não quer dizer que aquela produção ao passar ao largo seja menor do que aquelas artísticas que assumem isso como uma questão pros seus trabalhos. Eu acho que há uma diferença e quando você chama aquilo, apenas, de uma obra de arte, você abre mão dessa diferença, que é uma diferença até pra se potencializar a questão da loucura, potencializar no sentido de pensar a especificidade, a singularidade e o canal de expressão que essa consciência artística não dá conta (Camillo apud Wellisch, 2006, p. 59).

A irredutível diferença defendida por Camillo nos parece um caminho mais prudente de institucionalização da obra de Bispo de Rosário. Caso contrário, correse o risco de se perder de vista um conjunto de parâmetros e determinações que conferem legibilidade às obras. Em sua análise da obra de Bispo, Seligmann-Silva não parece desconsiderar tal diferença. Pois, para o autor, "a relação entre arte e "loucura" é fundamental para se entender o "desloucamento" que Bispo realizou sobre o sistema de signos artísticos" (Seligmann-Silva, 2007, p. 144). Sem dúvida, o interesse despertado pela obra de Bispo do Rosário passa pela fascinação que o colecionismo, a serialização, os arquivos, as listas e os inventários despertam nos estudos culturais, encanto explicado por e, de certo modo, complementar ao processo de digitalização do mundo, encontrado também nos escritos sagrados:

Vale lembrar que o próprio Genesis, nos versículos dedicados à narrativa de Noé, possui um caráter repetitivo de listagem de nomes. A sintaxe quebrada lembra também uma poética do acúmulo: "E viveu Muteselá cento e oitenta e sete anos, e gerou um filho. E chamou o seu nome Noé, dizendo: Este nos consolará acerca de nossas obras e do trabalho de nossas mãos [...] E era Noé da idade de quinhentos anos; e gerou Noé a Schem, Cham e Jafé (Seligmann-Silva, 2007, p. 146).

Se o sistema classificatório de Bispo é responsável por grande parte da atenção concedida a sua obra, não se pode perder de vista, no entanto, a apropriação de cada um dos objetos realizada pelo criador. Nesse sentido, cabe lembrar que "para confeccionar os trajes, utilizava tecidos de lençóis, cobertores e panos de chão, que bordava com fios desfiados dos uniformes dos internos. Aplicava sobre eles medalhas, cordões e todo tipo de materiais que recolhia, comprava ou ganhava" (Costa, 2009, p. 62). Tais procedimentos evocam as figuras do costureiro e do figurinista, sendo este o ponto de real importância aqui. Pois a recriação do mundo realizada por Bispo passa necessariamente pela costura e pelo entrelaçamento de objetos, em um registro de memórias, depoimentos, nomes e fatos que constitui um tecido visual extremamente rico, decorrente da capacidade de Bispo de objetivar as suas visões em coleções ma- 
teriais. Nesse sentido, pode-se dizer que a genialidade de Bispo reside justamente em sua capacidade de restituir ao sistema classificatório e enciclopédico a sua liberdade criadora. E isso não é trivial, pois

Bispo, o "louco", classificado com uma série de etiquetas psiquiátricas que o desclassificaram da vida extra-muros, reconstrói o mundo com seu colecionismo, organiza seu universo sob o signo de uma tipologia que estranha o mundo que o estranha. [...] Bispo [...] fazia da coleção de nomes e de objetos uma arte de "desloucamento" do mundo (Seligmann-Silva, 2007, p. 147 e149).

\section{O paradoxo e o vazio de Leonilson}

Há quem encontre um vínculo entre as poéticas de Arthur Bispo do Rosário e de Leonilson (1957 - 1993). Atesta-se tal conexão por uma soma de semelhanças, em especial, os fatos de ambos lançarem mão da costura - trabalhando a partir de elementos alheios às categorias tradicionais da arte - e de suas trajetórias serem marcadas por doenças tipicamente modernas.

Ao que parece, as aproximações param por aí. Pois, ao contrário de Bispo, Leonilson jamais fora um outsider. Antes sendo um viajante que deambula pelas capitais artísticas mundiais, o artista contabiliza, em vida, a participação em mais de setenta exposições, dentre as quais se destacam a Bienal de São Paulo, em 1985, e também a coletiva Como vai você, Geração 80?, realizada na Escola de Artes Visuais Parque Lage, em 1984, no Rio de Janeiro.

É, de certo modo, essa última mostra que serve como marco referencial dos primeiros anos de sua trajetória. Por mais problemática que seja, a sua consideração como integrante dessa geração parece evidenciar alguns dos procedimentos característicos do artista antes mesmo de seu mergulho nos bordados. Refere-se aqui ao que o crítico Wilson Coutinho chamou de "clima geracional" que conferia um temperamento a essa e outras exposições da época" , clima este "que os alimenta e torna seus trabalhos derivados de um mesmo processo imaginístico" decorrente da televisão, "o novo motor da história" (Coutinho, 2008, p. 247 - 249). Ressalta ainda:

o neo-expressionismo, o pattern de retorcidas formas coloridas, o rabisco rápido, a pintura agressiva, o mal pintado, o grafitismo, a recaptura da história da arte, a gestualidade agressiva, tudo isso parece determinar essa alegria, como marca antiintelectual desta geração. O antiintelectualismo os leva a fazer uma obra imediata, de sensibilidade rápida (Coutinho, 2008, p. 252).

Claro que o diagnóstico generalista e totalizante de Coutinho não é plenamente adequado à poética de Leonilson. Importa notar, no entanto, a preocupação pictórica7 do artista, preocupação esta que se manifesta nos trabalhos da primeira metade da década de 1980 por meio de uma apropriação de signos, códigos e objetos culturais de imediato reconhecimento. "Nessa obra", ressalta

\footnotetext{
${ }^{6}$ Refere-se aqui à exposição coletiva que Leonilson participou com Leda Catunda, Ciro Cozzolino, Cláudio Fonseca, Hilton Berredo e Sergio Romagnolo na Galeria Thomas Cohn em 1984. Coutinho irá, em sequência, elaborar criticas jornalísticas a esta e à exposição do Parque Lage, com os títulos
}

Transvanguarda no Brasil: os novos punks da pintura e Festa e democracia na arte do Parque Lage, publicados no Jornal do Brasil, respectivamente, em 01 de junho e 23 de julho de 1984. 
Riccioppo, "o uso de elementos da cultura comercial investe os trabalhos de alguma franqueza: esses elementos acabam por conferir à obra uma certa 'capacidade comunicativa'" (Riccioppo, 2010, p. 14).

A incessante apropriação que Leonilson realiza dos signos de uma cultura de massa internacional situam o artista no clima geracional descrito por Coutinho, merecendo destaque ainda o antiintelectualismo, abordado aqui como diretamente atrelado ao seu "sentimentalismo". Esse, por sua vez, deve ser compreendido não em sua chave melodramática, por meio da qual haveria a transmissão unívoca e imediata de seus sentimentos mais internos, sinceros e escondidos. $O$ viés expressivo na obra de Leonilson deve ser entendido, antes de mais nada, como um problema. Como tal, a sua obra é marcada por um movimento principal de "ambiguidade entre uma vontade de expressão e uma contenção melancólica" (Riccioppo, 2010, p. 23):

Repare-se, por exemplo, na constante polarização entre os temas e os procedi-
mentos das obras do artista ao longo dos anos. Por um lado, a obra parece lidar
com uma enorme dificuldade de comunicação, tantas vezes reiterada em imagens
de isolamento, solidão, em relações de escala que apequenam as figuras diante do
fundo, em registros escritos que indicam impotência frente ao mundo ("Leo não
consegue mudar o mundo", "o solitário", "o inconformado", "selfish", "o ilha",
entre tantos outros) e na série de dúvidas que assolam a imaginação desse trabalho
(dúvidas que transparecem na recorrência de pares antinômicos como "sim/não",
"verdade/mentira", "abismos/luzes"). Por outro lado, em uma atitude aparente-
mente mais assertiva, o artista usa, ao longo dos anos 1980, grandes extensões
de lona, cores vibrantes, pinceladas gestuais, uma iconografia que contabilizava
uma centena de ícones, todos referidos aos universos das histórias infantis, das
histórias em quadrinhos e da indústria cultural (Riccioppo, 2010, p. 24).

A descrição atenta fornecida por Riccioppo enfatiza um impasse insolúvel entre uma vontade de aproximação, ou de vínculo, em meio a um vazio desconcertante. A obra lírica, com isso, não parece afirmar a existência de um sujeito autocentrado e transcendental, mas a de um indivíduo isolado em seu próprio corpo. Dito de outro modo, uma questão existencial parece certamente funcionar como substrato para as imagens de Leonilson; só que aqui não se trata de um novo messias, mas de alguém que se debate com as frustrações de seu estar-no-mundo. Sob tal perspectiva, aquilo que a obra de Leonilson expressa é uma impossibilidade expressiva. Disponíveis aos olhares atentos e dispersos de terceiros, as imagens de Leonilson articulam um paradoxo, comunicando a sua incomunicabilidade.

É nesse sentido que se torna problemática uma afirmação como esta, de Paulo Herkenhoff: "Leonilson definiu um discurso extremamente intenso do sujeito, contra o experimentalismo epidérmico, apenas da superfície pictórica, que era comum nos artistas dos anos 80."8 Pois, o discurso promovido pelo artista parece colocar em xeque o próprio aparato discursivo, na medida em que revela uma mensagem que comunica, antes, um certo isolamento e privação. Sob essa ótica, a obra de Leonilson

7 A exposição Como vai você, Geração 80 ? é historicamente reconhecida por ter realizado um ressurgimento da pintura no país, à luz dos recentes movimentos internacionais da "transvanguarda italiana" e do "neo-expressionismo" alemão. Cabe lembrar aqui que Leonilson fora amigo do crítico italiano Bonito Oliva, principal responsável pela formulação das ideias que configuraram a transvanguarda em seu país. No contexto brasileiro, assim como em ambien- tes internacionais, o retorno à pintura não foi realizado sem críticas, como a desconfiança de Wilson Coutinho referente tanto à cópia do fenômeno estrangeiro quanto à instrumentalização capitalista da mostra, por meio da venda de produtos como catálogo, camisetas e o livro - normatizador - escrito por Roberto Pontual (Coutinho, 2008, p. 253). 
articula-se àquela de Eva Hesse, artista à qual ele nutria declarada admiração: "Pois, a voz de autoridade expressa através da imagem de Contingent transmitia uma mensagem de privacidade, de um recuo da língua, de uma retirada para territórios extremamente pessoais de experiência que estão além, ou aquém, do discurso" (Krauss, 1999, p. 92 - tradução nossa) ${ }^{9}$. O paradoxo descrito por Rosalind Krauss parece esclarecer a visão de Herkenhoff, visto que relaciona-se à ambiguidade encontrada na obra de Leonilson, mencionada anteriormente. Pois, a intensidade discursiva do sujeito encontrada na obra do artista cearense deve ser compreendida através da constatação de seus isolamento, fragilidade e imponência discursivos.

Em seus últimos anos, Leonilson produziu um conjunto de obras caracterizado pela coesão. É nesse período que ocorre a intensificação da costura como procedimento nuclear de sua poética, manifestando-se por meio de um grupo limitado de estratégias, como o recorte e o alinhavo de tecidos, a superposição e também a distribuição de pingentes, expressões e imagens bordadas sobre eles. Nas obras derradeiras, a costura parece sublinhar o vazio, conforme destaca Riccioppo:

O vazio, para Leonilson, demonstrava-se já excessivamente positivado naquele final da década de 1980. E quando o artista, nos anos subsequentes, começou a intensificar as costuras, era essa mesma constatação que se colocava para ele. Basta reparar na materialidade frágil e tênue de muitos desses trabalhos, como se evidenciassem um estado de saturação (é o caso de muitas obras em que o artista utiliza de tecidos como o voile); ou, no extremo oposto, no seu excesso de materialidade (como no caso de muitos que são feitos de feltro); ou, ainda, em seu caráter declaradamente decorativo (no caso de tecidos listados, estampados, em tecidos como o veludo) (Riccioppo, 2010, p. 114).

A costura, com isso, surge avivada na obra de Leonilson em um movimento acentuado de materialização do vazio. Nesse sentido, seus bordados diferem - e muito - daqueles produzidos por Bispo do Rosário, visto que os últimos tendem à coleção enciclopédica de um Noé contemporâneo à parte da história. As estratégias, portanto, não poderiam ser mais antagônicas, a despeito da semelhança de procedimentos.

\section{A costura do corpo de Letícia Parente}

Em 1975, a artista plástica Letícia Parente realizaria Marca Registrada, vídeo-performance que marcaria o surgimento da vídeo-arte no Brasil. Nessa obra, tem-se o processo de costura-escrita de Parente sobre a própria sola do pé esquerdo, onde ela costura a expressão industrial Made in Brasil. Tal atitude pode ser lida como um comentário da artista em relação ao contexto artístico de sua produção: criado por ocasião de uma mostra estrangeira e com uma máquina estrangeira, o vídeo responde ao convite para a exposição de modo semelhante ao produto destinado à exportação. Como toda mercadoria voltada para o comércio exterior, Letícia grava no pé o selo de qualidade brasileiro, costurando a marca de seu país. Com isso, a artista exporta

8 Tal afirmação foi veiculada na Folha de São Paulo em 02 de Junho de 1999, com uma reportagem de Fernando Oliva que levava o título de Leonilson ganha o MoMA.

9 "For the voice of authority that spoke through the image of Contingent was delivering the message of privacy, of a retreat from language, of a withdrawal into those extremely personal reaches of experience that are beyond, or beneath, speech." 
a si mesma, permitindo aos agentes externos dessa transação comercial identificar a sua procedência: fabricada no Brasil, diz o selo. Logo, Letícia afirma a produção brasileira de vídeo-arte ao mesmo tempo em que a desloca para fora do país.

Ironicamente, o selo costurado por Letícia define seu vídeo como produto cultural e artístico. Esse pensamento, presente na própria obra de arte, a respeito do circuito econômico e cultural no qual ela está inserida, aproxima Marca Registrada de outros trabalhos realizados na década de 70. Nesse período, destaca Luis Claudio da Costa, "afloravam questionamentos sobre a função da arte, o circuito e o mercado em que a obra se insere. Como fetiche de consumo e signo de status social, a obra de arte é entendida antes como parte de uma engrenagem do que como objeto cultural significante" (Costa, 2008, p. 27). No caso de Letícia, parece haver uma consciência por parte da artista de que a própria instância da vídeo-performance está sujeita ao mercado e ao processo de mercadorização. O gesto artístico parece apresentar, assim, uma consciência do circuito, ou do sistema de arte, em que o vídeo está inserido.

Essa consciência do sistema de arte está presente também na decisão de Letícia de operar com recursos tecnológicos recém-inventados e que não estariam, de antemão, inseridos no contexto produtivo da arte. Apresentar um vídeo, em 1975, como obra artística é uma atitude que lança uma série de questionamentos ao estatuto brasileiro da arte e suas instâncias de legitimação. Pois o vídeo de Letícia, além de partir de uma experimentação com um meio tecnológico novo, apresenta um processo de escrita sobre o pé como uma produção artística. A provocação de Marca Registrada reside no fato triplo de a obra ser um vídeo, um processo e também acontecer no pé. Esse fato triplo desautoriza um conjunto de pressupostos artísticos utilizados até então para situar ou legitimar uma criação.

$O$ ato de costurar pode ser considerado um processo de transformação do trabalho: uma costureira transforma, através da costura, uma matéria-prima, o tecido, em uma manufatura, a roupa. Nesse vídeo, o trabalho empreendido por Parente (a costura da artista) define o seu próprio corpo como matéria-prima (eliminando o tecido), em um processo de registro da marca nacional comum às mercadorias industriais. Agindo sobre si, Letícia costura conscientemente a marca registrada no pé: em um mesmo corpo, as mãos realizam a ação cujo local de atuação é o pé. Quando o corpo se torna o local de registro da marca nacional, a questão industrial ganha outras dimensões. A indistinção entre sujeito e objeto se, por um lado, produz uma equivalência entre os dois polos classicamente considerados como separados, por outro, revela um processo de reificação do ser humano, em que esse é tratado como mero objeto, como uma coisa a ser organizada de modo a garantir uma dada produção.

Letícia Parente, ao comentar o ato de costurar a própria pele, observa que "há um costume popular na Bahia em que se borda muito com uma linha na palma da mão e na sola do pé" (Parente, 2008, p. 76). É significativa essa apropriação: a artista recupera uma ação de sua terra natal, utilizando-a para registrar em sua sola uma expressão industrial. Em outros trabalhos da artista, a costura predomina sob a forma de manipulações de imagens corporais associadas à cirurgia plástica. Na série intitulada Mulheres, por exemplo, rostos femininos são construídos a partir de recortes, perfurações e colagens de imagens de revistas, havendo aí uma complementaridade entre a apropriação de imagens femininas encontradas em anúncios publicitários e o 
interesse da artista pela cirurgia plástica. Quando ela decompõe as faces de mulheres encontradas nas revistas para posteriormente recompor um novo rosto em que a cola, os pregos e os grampos atuam como elementos responsáveis por uma nova configuração, Letícia produz operações plásticas nas imagens humanas, operações essas que não são disfarçadas (como é o caso da cirurgia plástica que esconde as cicatrizes sob os cabelos), que impedem a produção de um efeito de naturalização. Os rostos de Letícia não são naturais, mas forjados por artifícios. O interesse pelas cicatrizes resultantes das cirurgias plásticas, em que tanto a pele quanto o papel são tratados como superfície de costura, sublinha o interesse de Letícia pelo processo e não pelo produto resultante das manipulações cirúrgicas.

Há que se destacar a sensibilidade de Letícia para o tema. Nos trabalhos aqui comentados, a cirurgia plástica realizada sobre o corpo humano ganha contornos variados, podendo ser associada a uma série de procedimentos utilizados com frequência nos dias atuais. Os metais utilizados para prender e reconfigurar as partes do corpo podem ser relacionados, por exemplo, às manifestações da body modification, nas quais os corpos são transformados intencionalmente por meio de inúmeras técnicas de transformações corporais, tais como tatuagens, piercings e outras perfurações, implantes estéticos e escarificações.

Dentre os artistas que propõem modificações corporais como experiências artísticas, destacam-se o australiano Stelarc, a francesa Orlan e também o primitivo moderno Fakir Musafar. Os três propõem situações performáticas nas quais seus respectivos corpos são submetidos a uma série de experiências cirúrgicas, eletrônicas, robóticas e virtuais. De modos diversos e variados, os artistas submetem seus corpos a uma série de radicalizações anatômicas, tornando-os locais híbridos e passíveis de contínuas costuras. Comum aos três é o corpo (tanto a sua estrutura quanto a sua representação) como material de transformações apresentadas publicamente. O modo como se relacionam com as colagens, os recortes e as perfurações de Letícia Parente reside na evidenciação dos artifícios e dos processos de modificação corporal. Se Letícia explora a costura superficial de sua sola do pé e as perfurações de rostos publicitários femininos através de pregos e grampos sobre o papel, Stelarc, Orlan e Musafar propõem mudanças anatômicas de suas partes corporais por meio de inserções e operações cirúrgicas. Apesar de apresentarem implicações diversas nesses trabalhos, é possível enxergar um elo entre eles, a partir da investigação do corpo como elemento artístico híbrido, tecido e costurado. Sob esta ótica, em meio à diversidade de estratégias utilizadas aqui pelos artistas comentados, nota-se um elemento transversal: o tratamento escancarado da costura do corpo, sem disfarces. Nesse sentido, todos atuam a contrapelo da padronização publicitária, na medida em que não deixam reduzir seus corpos à pura aparição imagética, impondo-lhes sucessivas reconfigurações que propõem um embate direto entre as estruturas anatômicas e suas representações.

\section{Arte ou artesanato? O alinhavo de Sheila Hicks}

No catálogo da trigésima Bienal de São Paulo, da qual foi uma das artistas participantes, Sheila Hicks é assim apresentada: 
Indiscutivelmente, uma das mais famosas artistas do mundo trabalhando com arte têxtil, durante mais de seis décadas ela atravessa as fronteiras entre pintura, escultura, design, desenho e forma tecida. Sheila Hicks estudou pintura na Universidade de Yale, sob a orientação de Josef Albers, onde foi inspirada pela teoria da Bauhaus; é por isso que ela rejeita limites tradicionais que separam arte, artesanato e design. A guinada para os têxteis em seu trabalho ocorreu após viajar muito e viver nas Américas Central e do Sul, onde foi seduzida por técnicas locais de tecelagem. A extensão de suas viagens e o contato com várias culturas ao longo da vida refletemse tanto no conceito como na forma final de suas peças em fibra, que variam em miniaturas a enormes encomendas arquitetônicas, fantásticas trepadeiras macias e tapetes etéreos de oração, empregando técnicas com ou sem tear. A obra da artista apresenta uma exploração criativa de técnicas tradicionais e não tradicionais, nas quais usa o fio para jogar com formas, divisões, assimetria, graus variáveis de tensão e relaxamento e, acima de tudo, de cor (Pérez-Oramas, 2012, p. 278).

Tal apresentação nos revela algumas chaves de leitura para a obra dessa artista, nascida em 1934 em Hastings (Nebraska, EUA). Ressalta-se, em primeiro lugar, a influência da Bauhaus na poética de Hicks, por meio de uma recomposição do vínculo entre arte e artesanato. Todavia, há que se observar a singularidade dessa reaproximação encontrada na poética da norte-americana. Pois, se tal entrelaçamento pautava-se, no caso da Bauhaus, pela associação entre arte e produção industrial - fazendo com que $\mathrm{o}$ artista se transformasse em industrial designer, produzindo, assim, "o protótipo com suas mãos, dirigindo a linha de produção" (Argan, 1992, p. 665) -, pode-se dizer que Hicks focaliza o estágio pré-industrial, na medida em que seu interesse reside em teares manuais e outros dispositivos cuja automação ainda conserva vínculos com a força humana. Em outras palavras, a artista não se transforma em designer, haja vista que o protótipo permanece enquanto tal, não servindo de modelo a nenhum tipo de produção em série. Justifica-se assim o interesse de Hicks por técnicas locais de tecelagem encontradas em sociedades pré-colombianas, interesse este surgido por estímulo do professor Josef Albers e de sua mulher, Anni Albers, exímia tecelã.

Sendo aluna de Albers, Hicks não apenas influencia-se pela teoria da Bauhaus, mas apropria-se do pensamento visual desenvolvido por seu mestre. "Todos os quadros de Albers", analisa Argan, "apresentam o mesmo esquema: quadrados inscritos um no outro e cobertos de camadas cromáticas uniformes, entre cujas quantidades implícitas de luz estabelece-se um relação ao mesmo tempo métrica e tonal, racional e perceptiva" (Argan, 1992, p. 519). Pode-se dizer que os tecidos, panos e objetos orgânicos construídos a partir de elementos têxteis, possuem os mesmos princípios que estruturam a obra de Albers. Na poética de Hicks, os quadrados são reduzidos às linhas e fios coloridos que, entrelaçados em diversos padrões, oferecem ao espectador uma experiência perceptiva próxima daquela proposta pelas pinturas de Albers. Interessante notar a argúcia de Hicks, na medida em que deixa de lado a tinta como principal elemento expressivo, utilizando em seu lugar a linha. A despeito do material utilizado, a preocupação cromática é transversal às poéticas de ambos os criadores.

Se as obras de Hicks remetem às tapeçarias produzidas em diversos contextos históricos - a título de exemplo, a tapeçaria de Bayeux, datada de 1.080, ou os tapetes persas do século XVII - elas, por outro lado, conservam um estreito diálogo com a produção artística que lhes é contemporânea. Não à toa, a artista se refere a suas obras como abstrações têxteis (textile-based "abstractions"), pois verifica-se a ausência de 
elementos figurativos, havendo uma ênfase na percepção formal das obras. Em obras monocromáticas, como Blue Letter (1959), Wall Hanging (1961) e Greta Weaving (1961), em meio à homogeneidade da cor têxtil, salta aos olhos os diversos arranjos produzidos pela artista, por meio de um entrelaçamento de estratégias de tecelagem díspares que criam uma espécie de grafia têxtil inteligível apenas perceptivamente. Blue Letter é, nesse sentido, significativo, por se tratar de um pedaço quadrado de trama azul de bordas irregulares, preso à parede: que espécie de escrita seria aquela que não a costura e o entrelaçamento das linhas que tecem a superfície cromática?

As características acima mencionadas aproximam a poética de Hicks ao pósminimalismo ${ }^{10}$, na medida em que suas obras apostam em uma materialidade que a distancia das práticas minimalistas e da arte conceitual. Sob tal perspectiva, atesta-se similaridades entre o trabalho da artista norte-americana e aquele de Eva Hesse ${ }^{11}$, dada a ênfase de ambas as artistas em trabalhos que aparentem estar inacabados e incompletos, sem que saibamos ao certo se estão em processo de fazer-se ou desfazer-se. Tal como Hesse, Hicks também não se limita à esfera "pictórica", apresentando um conjunto considerável de trabalhos que ocupam o espaço real em escalas, por vezes, monumentais. May I Have This Dance? (2002-03), por exemplo, é uma cascata têxtil que surge anexada no alto do canto superior do teto e desagua no chão do espaço expositivo. Formada por cilindros maleáveis cobertos de tecidos de variadas cores, a obra revela-se como um convite para o espectador dançar fenomenologicamente em torno desta.

A monumentalidade de alguns trabalhos, bem como a delicadeza de outros; a aproximação entre arte e artesanato; o vínculo entre modos de produção ocidentais e não ocidentais; a atuação na esfera artística e fora dela12: observa-se, na poética de Hicks, a implosão da lógica binária das linhas divisórias por meio da oscilação entre polos aparentemente antagônicos. Suas linhas, com isso, mais tramam do que separam, impondo dificuldades bem-vindas ao exercício de categorização. Sob essa ótica, a poética de Hicks parece libertar a tecelagem do jugo da funcionalidade, devolvendo-lhe o poder metafórico, encontrado já nos escritos gregos que servem de origem reflexiva sobre as artes no ocidente ${ }^{13}$.

\section{Cindy Sherman: o dispositivo fotográfico como figurino}

A nosso ver, a presente reflexão - que não se pretende exaustiva - incorreria em erro grave caso excluísse o trabalho de Cindy Sherman para a observação do figurino para além do acontecimento teatral. Pois, ao longo de sua carreira, a artista norte-americana criou um conjunto de retratos - sendo simultaneamente figurinista, performer, fotógrafa, diretora de arte etc. - que sublinha a condição pósmoderna da arte contemporânea. Tal afirmação deve ser compreendida, sobretudo tendo em vista a saturação de imagens que condiciona o mundo atual, tornando

\footnotetext{
10 O termo Pós-Minimalismo não é preciso, abarcando um conjunto de práticas artísticas díspares, tais como Process Art, Arte Povera, Performance Art, Body Art, Installation e Site-specific Art. Ele não deve ser compreendido como um movimento posterior ao desenvolvimento do Minimalismo, mas como uma "reação veloz e furiosa". Constata-se o embate quando se tem em mente que a exposição Primary Structures, focalizada na prática minimalista, se deu no mesmo ano que Eccentric Abstraction, que mostrava alternativas a esta. Por-
}

tanto, trata-se, nas palavras de Hal Foster, de um simultânea "rodada inebriante de posição e contraposição, exposição e contra-exposição" (tradução nossa) "heady round of position and counterposition, show and countershow") (Krauss et al.: 2011, p. 578).

11 Assim como Hicks, Eva Hesse também estudou na Yale University na década de 60, tendo sido aluna de Josef Albers e George Kubler. 
ingênua qualquer tentativa de acesso à realidade ${ }^{14}$. O caso de Sherman é exemplar, pois seus retratos apresentam, sem exceção, a condição de "serem cópias destituídas de original" (Krauss, 2009, p. 102 - tradução nossa) ${ }^{15}$.

Sendo assim, há que se contestar o argumento segundo o qual Sherman "usou o recurso mais antigo à disposição, contar uma história, e o revigorou na arte visual" (Tomkins, 2009, p. 39). Por mais que a artista adote inúmeros personagens, não são narrativas que ela deseja transmitir - não parece residir aí o seu mérito artístico. Dito de outro modo, há que se desconfiar das personagens de Sherman. Tal postura é sugerida por Rosalind Krauss, quando a crítica lança mão do mito, tal como ele é definido por Roland Barthes, para analisar a obra aqui focalizada. Grosso modo, para o pensador francês, o mito seria responsável pela inversão da cultura em natureza: "aquilo que não passa de um produto da divisão de classes e das suas sequelas morais, culturais, estéticas é apresentado (enunciado) como 'óbvio por natureza'" (Barthes, 2004, p. 77). Sendo assim, a determinação histórica de um signo lhe é camuflada por uma aparência a-histórica, imutável e natural que the confere o mito. Tendo o aparato teórico barthesiano em mente, restariam duas opções ao leitor do mito: crer em seu significado mítico, embarcando na aparência natural; ou, por outro lado, propor a sua desarticulação, a fim de evidenciar a sua contingência histórica.

De acordo com Krauss, a primeira estratégia - qual seja, aquela do leitor que crê no mito - caracterizaria a opinião daqueles pensadores que consideram Sherman uma contadora de histórias. Ao lado de Calvin Tomkins, estariam também Arthur Danto e Peter Schjeldahl, dentre outros leitores considerados pela autora como consumidores de mito "firmemente calcados no significado" (Krauss, 2009, p. 124 - tradução nossa) ${ }^{16}$. Em contraste com essa postura analítica, Krauss sugere que olhemos os retratos de Sherman por debaixo dos panos (under the hood). Como isso seria possível?

Olhar por debaixo dos panos requer que consideremos o figurino na obra de Sherman não apenas diretamente concernente às roupas e acessórios utilizados pela artista. Ele seria aqui, antes de tudo, um sistema complexo, composto pelos elementos que acabamos de mencionar, mas também por todo um conjunto de significantes que inclui o enquadramento, a iluminação, a distância, o ângulo da câmera e demais aspectos técnico-expressivos utilizados por Sherman em cada um de seus retratos. Cada figura criada pela artista torna-se então uma função de diversas variáveis. Pois o personagem é constituído por um conjunto de códigos e operadores que, por sua vez, são camuflados pela aparência mítica de sua substância individual. O figurino, nesse caso, é o retrato, ou melhor, a cena. E, assim, sublinhamos o paradoxo: como elemento artístico autônomo, o figurino amplia-se de modo a ser traduzido em dispositivo.

\footnotetext{
12 Hicks também realizou alguns trabalhos comerciais, como a sua atuação como consultora de design para a Knoll Associates ou ainda as decorações em seda branca produzidas para o interior de aviões Boeing 747.

13 Para uma análise mais detida do poder metafórico da tecelagem, veja-se 0 texto de Arthur Danto Weaving as Metaphor, encontrado no livro homônimo publicado por ocasião da retrospectiva de Sheila Hicks.
}

14 Trata-se de uma consideração problemática, sobretudo quanto à desconfiança referente a um possível contato com o real. Deixamos para outro momento delinear os limites e as contradições desta condição pós-moderna. 15 "being a copy without original". 


\section{Outros artistas à guisa de conclusão}

O conjunto de artistas aqui analisado se caracteriza pela divergência de estratégias artísticas. Se o ponto de partida desta análise foi tentar observar o figurino para além do contexto teatral tradicional, tal viés (como pôde ser observado) não propôs uma costura unidirecional e homogênea das poéticas de Bispo do Rosário, Leonilson, Sheila Hicks, Letícia Parente e Cindy Sherman. Antes de tudo, o intuito aqui foi o de reforçar as diversas possibilidades do fazer artístico na atualidade, levando em conta um conjunto de procedimentos comumente associado ao ofício do figurinista.

Como se disse em momento precedente, não se trata de uma análise extenuante a fim de se produzir mapeamentos e panoramas do circuito de arte; comprova tal argumento uma quantidade considerável de artistas cujas poéticas evidenciam artifícios de costura e/ou utilização de roupas e acessórios como elementos plásticos. Veja-se, por exemplo, a sul-africana Mary Sibande, cuja obra apresenta algumas proximidades com a de Cindy Sherman. Se, no trabalho desta, "nós nunca vemos Sherman como Sherman, pois ela está sempre representando alguém, e o que pareceria a sua nudez é uma ilusão resultante de próteses corporais, vestidas como máscaras" (Danto, 2001, p. 234 - tradução nossa) ${ }^{17}$, em Sibande, os retratos fotográficos e escultóricos de Sophie - alterego criado a partir de sua própria aparência - reinterpretam a sua história familiar que, por sua vez, funciona como elo metonímico das transformações sociopolíticas de seu país.

Como Sibande, a colombiana Doris Salcedo parte de heranças bárbaras da história recente de seu país. Em Atrabilious (1992-1993), ela utiliza sapatos velhos acondicionados em pequenas caixas dentro da parede da galeria seladas por fibras orgânicas translúcidas para evocar as vítimas desaparecidas por ocasião da guerra civil na Colômbia, bem como a aridez informacional a respeito dessas por parte de seus familiares. A presença do ausente também engendra muitas obras do francês Christian Boltanski, em especial a instalação Personnes, apresentada por ocasião da Monumenta 2010, no Grand Palais, Paris. Nesse trabalho, o artista utiliza toneladas de roupas dispostas de dois modos distintos: uma enorme montanha situada no eixo da nave central do edifício, sobre a qual está uma grua mecânica que, a intervalos regulares, apanha um punhado de vestimentas, o eleva para, em seguida, o soltar. As roupas pendem por breves momentos no ar, retornando ao monte de onde saíram. Além deste gigantesco amontoado, Bolstanki cobre o chão do Grand Palais com sobretudos, casacos e outras vestimentas velhas, organizadas em 69 retângulos de três por cinco metros, sob o som de uma quantidade considerável de batidas de coração, que, juntas, conferem uma impressão sonora industrial. Assim como em outros trabalhos, Bolstanki, "o mestre da exposição como meio" (Obrist, 2010, p. 127), segundo Harald Szeemann, focaliza os limites da memória e os rastros das vítimas do processo civilizatório. As roupas, neste sentido, funcionam como índices indeléveis de vidas já invisíveis.

Boltanski, Sibande e Salcedo unem-se a uma coleção de artistas que descarta os meios artísticos tradicionais para forjar novas maneiras de criação, lançando mão 
de habilidades e elementos comuns à profissão do figurinista. Dentre inúmeros criadores, podemos, por fim, mencionar Márcia X (Brasil), Daniel Toledo (Brasil), João Penoni (Brasil), Laura Lima (Brasil), Papa Ibra Tall (Senegal), Michelangelo Pistoletto (Itália), Piergiorgio Colombara (Itália), Ilene Segalove (EUA), Marya Kazoun (Líbano), Yiqing Yin (China), Hans Eijkelboom (Holanda), Nikhil Chopra (Índia), Moshekwa Langa (África do Sul), Ahmad Askalany (Egito), Falke Pisano (Holanda), Tomas Saraceno (Argentina), Lucio Fontana (Argentina - Itália), Nelson Leirner (Brasil), Michel Groissman (Brasil) e Rebeca Horn (Alemanha).

\section{Referências}

ARGAN, Giulio Carlo. Arte Moderna. São Paulo: Companhia das Letras, 1992.

BARTHES, Roland. O rumo da língua. São Paulo: Martins Fontes, 2004.

COLACELLO, Bob. The Subject as Star. In: Vanity Fair, Dezembro de 2006.

COSTA, Cacilda Teixeira. Roupa de Artista - o vestuário na obra de arte. São Paulo: Imprensa Oficial do Estado de São Paulo: EDUSP, 2009.

COSTA, Luis Claudio. Letícia Parente: a videoarte como prática da divergência. In: PARENTE, André (Org.). Preparações e Tarefas - Letícia Parente. São Paulo: Paço das Artes, 2008.

COUTINHO, Wilson. Imediações: a crítica de Wilson Coutinho. Rio de Janeiro, Conexão FUNARTE Artes Visuais, 2008.

DANTO, Arthur C. The madonna of the future - essas in a pluralistic art world. New York: Farrar, Straus and Giroux, 2001.

DECTER, Joshua. Radiação urbana: reflexões sobre a vida e a obra de Keith Haring. In: Catálogo da exposição Keith Haring. Centro Cultural Banco do Brasil, 2003.

DIDI-HUBERMAN, Georges. O que vemos, o que nos olha. São Paulo: Ed. 34, 1998.

GALIZIA, Luiz Roberto. Os Processos Criativos de Robert Wilson - trabalhos de arte total para o teatro americano contemporâneo. São Paulo: Perspectiva, 2004.

GIONI, Massimiliano. Is everything in my mind? In: Catálogo da 55 Bienal Internacional de Veneza. Volume 1. Itália, Maio de 2013.

GONZALEZ-TORRES, Felix. Entrevista a Hans Ulrich Obrist. In: OBRIST, Hans-Ulrich. Entrevistas: volume 5. Rio de Janeiro: Cobogó; Belo Horizonte, MG: Instituto Cultural Inhotim, 2011. 
KRAUSS, Rosalind, BOIS, Yve-Alain, BUCHLOH, Benjamin H.D., FOSTER, Hal e JOSELIT, David. Art since 1900. Modernism, antimodernism, postmodernism. Nova York: Thames \& Hudson, 2011.

KRAUSS, Rosalind. Bachelors. Massachusetts: MIT Press, 1999.

LAGNADO, Lisette. São Tantas as Verdades. São Paulo: Projeto Leonilson; SESI, 1995. OBRIST, Hans Ulrich. Uma breve história da curadoria. São Paulo: BEI Comunicação, 2010.

ORLAN. O manto de Arlequim. In: LABRA, D. (Org.) Performance Presente Futuro. Rio de Janeiro: Contra Capa Livraria / Automática, 2008.

PARENTE, André (org.) Preparações e Tarefas - Letícia Parente. São Paulo: Paço das Artes, 2008.

PÉREZ-ORAMAS, Luiz. Catálogo da 30 Bienal de São Paulo: $A$ iminência das poéticas. São Paulo: Fundação Bienal de São Paulo, 2012.

PIRES, Beatriz Ferreira. O corpo como suporte da arte: piercing, implante, escarificação, tatuagem. São Paulo: SENAC/São Paulo, 2005.

RICCIOPPO, Carlos Eduardo. Leonilson, 1980-1990. São Paulo, 2010. Dissertação (Mestrado) - Escola de Comunicações e Artes/ECA-USP, Universidade de São Paulo.

SABINO, Marco. Dicionário da moda. Rio de Janeiro: Campos, 2007.

SELIGMANN-SILVA, Marcio. Arthur Bispo do Rosário: a arte de "enlouquecer" os signos. In: IEL-UNICAMP: Revista Artefilosofia n. 3, Julho de 2007.

SILVESTRE FRIQUES, Manoel. Cenas Transversais - análise de algumas produções de Bob Wilson na última década. Anais do VI Congresso de Artes Cênicas - ABRACE, 2010.

SONTAG, Susan. Doença como metáfora, AIDS e suas metáforas. São Paulo: Cia das letras, 2007.

STELARC. Dos Zumbis aos corpos cyborgs: carne fractal, máquinas quimeras e órgãos extras. In: LABRA, D. (Org.) Performance Presente Futuro. Rio de Janeiro: Contra Capa Livraria / Automática, 2008.

TOMKINS, Calvin. As vidas dos artistas. São Paulo: BEI Comunicação, 2009. 
WELLISCH, Cecilia Gusmão. A invenção de Bispo do Rosario. Rio de Janeiro, 2006. Dissertação (Mestrado) - Departamento de Letras, Pontifícia Universidade Católica do Rio de Janeiro (PUC-RJ).

Catálogo Voom Portraits. São Paulo: SESC Pinheiros, 2008.

http://www.nytimes.com/2007/01/30/arts/design/30wils.html

http://www.vanityfair.com/culture/features/2006/12/wilson200612

http://www.moma.org/interactives/exhibitions/2010/warhol/\#

http://oglobo.globo.com/cultura/a-arte-de-bispo-do-rosario-sem-negar-loucura-9305552

http://www.artinamericamagazine.com/news-opinion/news/2011-04-04/sheila-hicks/ http://www.theguardian.com/artanddesign/2012/aug/26/new-africa-south-african-artist http://www.spencerart.ku.edu/collection/recent/sibande.shtml

http://www.artthrob.co.za/Artbio/Mary_Sibande_by_Anna_Stielau.aspx

http://www.citypress.co.za/lifestyle/purple-shall-govern/

http://www.blog.standardbank.com/arts/2013/07/mary-sibande-s-purple-reign

http://africlectic.com/mary-sibande-art-imitates-life/

http://sa-venice-biennale.com/artists/lyndi-sales/

http://afritorial.com/mary-sibande/

Recebido em 19/05/2014

Aprovado em 13/06/2014 